\title{
Environmental shaping of the bacterial and fungal community in infant bed dust and correlations with the airway microbiota
}

Shashank Gupta ${ }^{1}$, Mathis H. Hjelmsø $\varnothing^{2}$, Jenni Lehtimäki ${ }^{2}$, Xuanji Li ${ }^{1}$, Martin S. Mortensen ${ }^{1,3}$, Jakob Russel ${ }^{1}$, Urvish Trivedi ${ }^{1}$, Morten A. Rasmussen ${ }^{2,4}$, Jakob Stokholm², Hans Bisgaard ${ }^{2}$ and Søren J. Sørensen ${ }^{1 *}$ (I)

\begin{abstract}
Background: From early life, children are exposed to a multitude of environmental exposures, which may be of crucial importance for healthy development. Here, the environmental microbiota may be of particular interest as it represents the interface between environmental factors and the child. As infants in modern societies spend a considerable amount of time indoors, we hypothesize that the indoor bed dust microbiota might be an important factor for the child and for the early colonization of the airway microbiome. To explore this hypothesis, we analyzed the influence of environmental exposures on 577 dust samples from the beds of infants together with 542 airway samples from the Copenhagen Prospective Studies on Asthma in Childhood 2010 cohort.

Results: Both bacterial and fungal community was profiled from the bed dust. Bacterial and fungal diversity in the bed dust was positively correlated with each other. Bacterial bed dust microbiota was influenced by multiple environmental factors, such as type of home (house or apartment), living environment (rural or urban), sex of siblings, and presence of pets (cat and/or dog), whereas fungal bed dust microbiota was majorly influenced by the type of home (house or apartment) and sampling season. We further observed minor correlation between bed dust and airway microbiota compositions among infants. We also analyzed the transfer of microbiota from bed dust to the airway, but we did not find evidence of transfer of individual taxa.

Conclusions: Current study explores the influence of environmental factors on bed dust microbiota (both bacterial and fungal) and its correlation with airway microbiota (bacterial) in early life using high-throughput sequencing. Our findings demonstrate that bed dust microbiota is influenced by multiple environmental exposures and could represent an interface between environment and child.
\end{abstract}

Keywords: House dust, Bacterial microbiome, Fungal microbiome, Airway microbiome, Infant microbiome

\footnotetext{
* Correspondence: sjs@bio.ku.dk

'Section of Microbiology, Department of Biology, University of Copenhagen, Universitetsparken 15, bldg. 1, DK2100, Copenhagen, Denmark

Full list of author information is available at the end of the article
}

(c) The Author(s). 2020 Open Access This article is licensed under a Creative Commons Attribution 4.0 International License, which permits use, sharing, adaptation, distribution and reproduction in any medium or format, as long as you give appropriate credit to the original author(s) and the source, provide a link to the Creative Commons licence, and indicate if changes were made. The images or other third party material in this article are included in the article's Creative Commons licence, unless indicated otherwise in a credit line to the material. If material is not included in the article's Creative Commons licence and your intended use is not permitted by statutory regulation or exceeds the permitted use, you will need to obtain permission directly from the copyright holder. To view a copy of this licence, visit http://creativecommons.org/licenses/by/4.0/ The Creative Commons Public Domain Dedication waiver (http://creativecommons.org/publicdomain/zero/1.0/) applies to the data made available in this article, unless otherwise stated in a credit line to the data. 


\section{Background}

As societies become more modernized, people tend to spend an increasing amount of time indoors, especially within their homes [1]. Here, humans are exposed to a large number of microbes, which can have important implications for health and disease. With the advancement of sequencing technologies, it is now possible to study the indoor microbiome [2-4] and how microbes therein affect the inhabitants [5, 6]. Most studies to date have characterized the indoor microbiome in schools, homes, offices, hospitals, or kindergarten classrooms [5, 7-10]. In homes, studies were mostly done on floors, kitchen sinks, and bathrooms [5, 11]. However, very little is known about microbial communities present in beds with which humans have extended daily exposure [12].

Environmental factors such as pets, type of housing, and land use of the surrounding area have been associated with the microbiota of homes [2, 13, 14]. Many published studies have looked at the influence of pets in homes, but none have addressed a pet's influence on the bed microbiome. Many pet owners share their bedroom space with their pets [15]; therefore, the pets may influence the bed dust composition, including health relevant taxa, as microbes can be airborne and get enriched in closed systems. Some studies reported that the exposure to pets (e.g., dogs and cats) decreases the risk of allergic diseases [16-18], where another has shown increased risk [19]. With the reasonably consistent findings across studies, exposure to pets, specifically dogs, remains a promising approach for identifying a prevention strategy for allergic diseases in early life.

Furthermore, especially among young infants, the bed dust is a highly relevant place of sampling for capturing the indoor dust microbiota, which can serve as a proxy for many environmental exposures and act as a seeding source for the microbiota colonizing the child. Early infancy characterizes a rapid developmental phase of the airway microbial colonization [20] but also with regard to immune function [21]. Elucidating the relationship between the indoor and infant airway microbiome in early life could be important in understanding human development, especially as the early life airway microbiota has been associated with later asthma development $[22,23]$. The relationship between microbial exposures from surroundings and the composition of the infant airway microbiota is still poorly understood [24, 25].

In this study, we evaluate which environmental factors influence the bacterial and fungal composition of the infants' beds at 6 months after birth. Additionally, we compare bed dust to the bacterial composition of the airways at age 3 months. All samples were collected in the Copenhagen Prospective Studies on Asthma in Child$\operatorname{hood}_{2010}($ COPSAC 2010$)$ cohort [26]. Through a comprehensive analysis of the microbiomes in bed dust and early life airways, we aim to elucidate the interactions between the two and secondarily identify the external factors that affect the microbial interactions between bacterial and fungal microbiome. To our knowledge, this is the first study to provide detailed qualitative and quantitative descriptions of microbial taxa and diversity in bed dust.

\section{Results}

\section{Characteristics of the cohort}

In this study, we included 584 bed dust samples collected from the infants' beds at 6 months after birth and 658 airway samples collected from the infants 3 months after birth. The demographic information about the study population in this study is summarized in Table S1.

\section{Sequencing results and quality control}

In total, for the 584 dust samples and 70 controls (including negative and positive controls) obtained from the bed of the cohort children at age 6 months, we had $65,183,188$ and $57,936,573$ raw reads, from $16 \mathrm{~S}$ ribosomal RNA gene (16S rRNA gene) (V3-V4 region) and internal transcribed spacer (ITS) amplicon (ITS2 region) sequencing including controls, respectively. After quality filtering and chimera detection, amplicon sequences were clustered into 79,347 and 24,474 amplicon sequence variants (ASVs) for 16S rRNA gene and ITS data. The coverage of our sequencing was assessed by rarefaction curves, showing a beginning plateau at 10 , 000 reads per sample (Fig. S1a and b). After removing the negative controls and the samples that did not reach a satisfactory read depth (minimum 3000 reads), we were left with 577 samples, representing 49,371 and 20, 211 unique bacterial and fungal ASVs.

In the total 658 airway samples obtained from the cohort from children at age three, 34,319,874 raw reads passed quality filtering. After quality filtering and chimera detection, amplicon sequences were clustered into 3,692 ASVs for 16S rRNA gene (V4 region) data. We removed airway samples without a matching bed dust sample from the downstream analysis, ending up with 542 samples that contained a total of 2,272 ASVs.

\section{Microbial community composition in bed dust}

A total of 930 bacterial genera from 31 phyla were detected in the beds of 6-month-old infants. The most abundant phyla were Firmicutes (43.05\%), Proteobacteria (25.69\%), Actinobacteria (19.27\%), Cyanobacteria (6.89\%), Bacteroidetes (2.17\%), and Fusobacteria (1.85\%) (Fig. 1a, Fig. S3a, Table S2). The remaining 25 phyla combined represented $1 \%$ of the relative abundance. Taxonomic identification at the class, family, and genus levels (Fig. S3b, c, and d, respectively) revealed that most of the Firmicutes belonged to the class Bacilli, with 
a

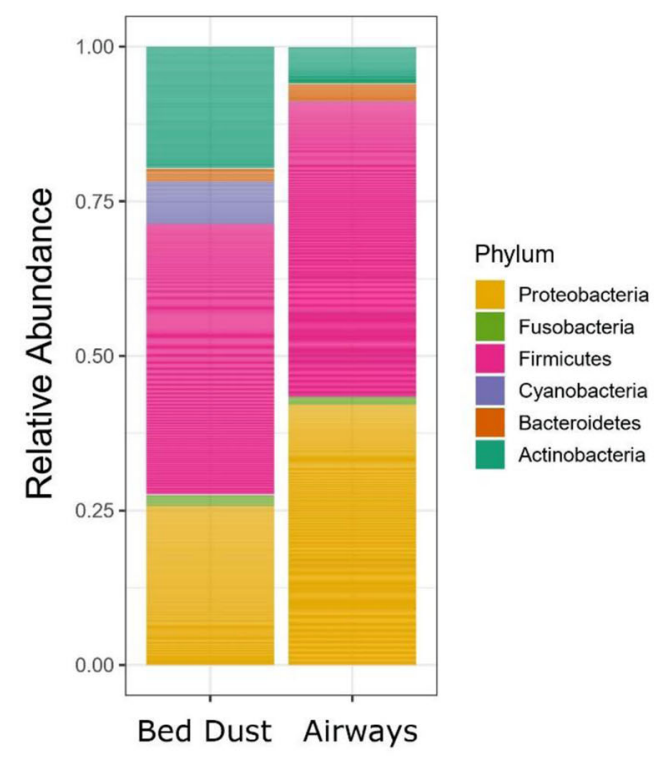

b
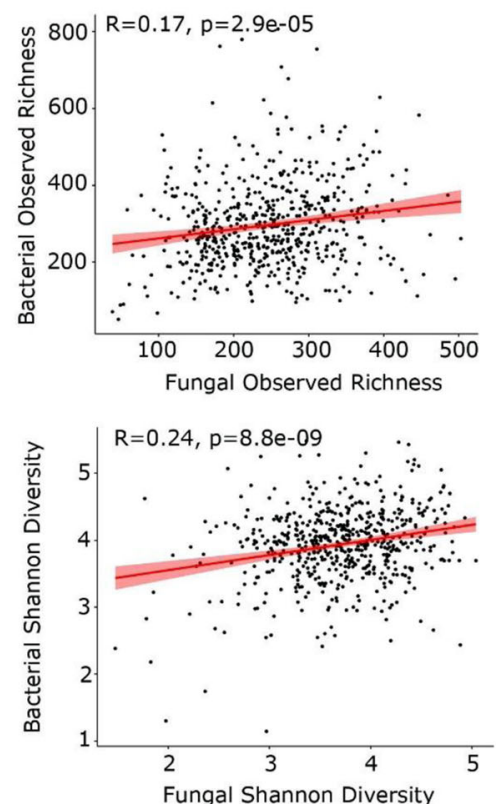

Fig. 1 a Relative abundance of bacterial phyla in bed dust and airway samples. Phyla with a mean abundance of at least 1\% abundance across bed dust samples are represented in colors. b Associations between fungal and bacterial alpha diversity (observed richness and Shannon diversity index values) for a given sample. The shaded gray region represents $95 \%$ confidence intervals. Linear regression analysis: $p=2.9 \mathrm{e}-05, R=0.17$ for observed richness and $p=8.8 \mathrm{e}-09, R=0.25$ for Shannon diversity

varying amounts of the families Streptococcaceae and Staphylococcaceae. Among these, the most abundant genera were Streptococcus (23.6\%), Staphylococcus (12.43\%), Rothia (6.17\%), Haemophilus (4.15\%), Paracoccus (4.12\%), and Corynebacterium (4.09\%) (Table S3).

A total of 102 fungal genera from 6 phyla were detected. The most abundant phyla were Ascomycota (82.47\%) and Basidiomycota (6.60\%) (Fig. S4a, Table S4). The remaining four phyla represented less than $1 \%$ of the overall abundance with an additional $10.53 \%$ of the sequences not classified at the phylum level (Fig. S4b, Table S4). A similar trend was observed at the family level (Fig. S4c) and class level (Table S5). The most abundant genera were Spegazzinia (9.61\%), Aureobasidium (5.34\%), Sphaerellopsis (4.99\%), Curvularia (4.83\%), Saccharomyces (4.50\%), and Penicillium (3.55\%) (Fig. S4d, Table S6), with $44.1 \%$ of reads being unclassified Ascomycota.

\section{Correlations between the bacteria and fungi in bed dust}

We explored the relationship between the bacterial and fungal members in the bed dust microbiota of the children at 6 months. Bacterial and fungal alpha diversity values were positively correlated $\left(r_{\text {observed }}=0.17, r_{\text {shannon }}\right.$ $=0.24)$, when assessed by linear regression $\left(p_{\text {observed }}=\right.$ $\left.2.9 \mathrm{e}-05, p_{\text {shannon }}=8.8 \mathrm{e}-09\right)($ Fig. 1b). We further looked at the correlation both within and between the fungal and bacterial microbiomes for the genera present in at least $30 \%$ of the samples $(n=173)$. For fungal-fungal correlation, most of the significant correlations $(p<$ 0.01) were positive, while correlations between Saccharomyces with Spegazzinia (Spearman correlation coefficient, $r=-0.15$ ), Curvularia (Spearman correlation coefficient, $r=-0.23$ ), Sphaerellopsis (Spearman correlation coefficient, $r=-0.19$ ), and Neophaeosphaeria (Spearman correlation coefficient, $r=-0.13$ ) were negative (Fig. S5). The strongest positive correlation occurred between Spegazzinia and Curvularia (Spearman correlation coefficient, $r=0.54$ ), while Curvularia and Saccharomyces (Spearman correlation coefficient, $r=-0.23$ ) exhibited the strongest negative correlation.

A higher number of significant correlations were found for bacteria-bacteria correlation compared to fungal-fungal correlation. The strength of negative correlation is very low in bacteria-bacteria correlation (Spearman correlation coefficient, $(r)$ range from -0.12 to - 0.28). For example, the genera Sphingomonas was significantly correlated $(p<0.01)$ with more than 30 genera; most correlations were positive (Spearman correlation coefficient, $(r)$ range from 0.15 to 0.72 ) and showed negative correlations with 10 genera (Spearman correlation coefficient, $(r)$ range from -0.12 to -0.16 ). Peptoniphilus genera showed the strongest positive correlation with Finegoldia (Spearman correlation coefficient, $r=0.75$ ). We also observed many clinically relevant genera that were significantly correlating with 
many other genera, for example, Moraxella showed strongest positive correlation with Abiotrophia genus (Spearman correlation coefficient, $r=0.32$ ), whereas Staphylococcus showed the strongest positive correlation with Corynebacterium (Spearman correlation coefficient, $r=0.6)$ and strongest negative correlation with Streptococcus (Spearman correlation coefficient, $r=-0.27$ ). On the other hand, Streptococcus shows significantly positive correlation with Gemella (Spearman correlation coefficient, $r=0.64$ ) (Fig. S6).

We next assessed the correlations between the fungal and bacterial microbiota at the genus level. Comparing the relative abundances, both positive and negative correlations existed between fungal and bacterial taxa (Fig. 2). Cutibacterium and Malassezia showed the strongest inter-domain positive correlation (Spearman correlation coefficient, $r=0.43$ ), whereas Prevotella with Erythrobasidium (Spearman correlation coefficient, $r=-0.25$ ) exhibited the strongest negative correlation.

\section{Environmental factors shaping the bed dust microbiome} The effect of environmental factors on the bed dust microbiome, i.e., income level, type of home, type of living environment, pets, season of dust sample collection, race, and number of male or female siblings, was evaluated (Table 1). The bacterial richness in the bed dust was significantly affected by the type of home (house or apartment, median richness 294 and 269, respectively), type of living environment (rural or urban, median richness 298 and 267, respectively), and pets (cat and dog vs no pets, median richness 346 and 273 , respectively) (Wilcoxon test, adjusted $p=0.0089$, adjusted $p=0.0004$, and adjusted $p=0.00045$, respectively). We investigated the bacterial richness in the apartment and house locating either in the rural and urban areas. Apartments in rural areas showed significantly higher bacterial richness compared to apartments in urban areas (apartments in rural vs urban, median richness 302 vs 263) (Wilcoxon test, adjusted $p=0.024$ ) while houses had no significant differences between rural and urban areas (Fig. S7a). On the other hand, bacterial richness between houses and apartments in rural and urban areas was not significantly different (Fig. S7b).

The fungal richness was significantly affected by the type of home (house or apartment, median richness 251 and 230, respectively) and the season of sampling (median richness for summer 262, winter 233, spring 266, and autumn 229) (Kruskal-Wallis test, adjusted $p=1.3 \mathrm{e}$ -05). The samples collected in spring and summer showed a higher fungal diversity. We further investigated the fungal richness into the apartment and house present in the rural and urban areas, and we did not observe any significant differences (Fig. S8a). On the other hand, fungal richness between house and apartment in urban areas was significantly different (house vs apartment in urban areas, median richness 255 vs 228) (Wilcoxon test, $p=0.003$ ) (Fig. S8b), whereas the houses and apartments present in rural areas were not.

Moreover, siblings correlated with an increased bacterial (no vs yes, median richness 265 vs 298) (Wilcoxon test, adjusted $p=0.03$ ) and fungal richness (no vs yes, median richness 226 vs 255) (Wilcoxon test, adjusted $p$ $=0.0023)$. We further observed that homes that had only male siblings showed significantly higher bacterial richness compared to homes that had no siblings (median richness 311 vs 265) (Wilcoxon test, adjusted $p=$ 0.0079). However, homes that had only female siblings did not show any significant difference (median richness 265 vs 284) (Wilcoxon test, adjusted $p=0.4$ ). Moreover, fungal richness correlated with male and/or female siblings (median richness for no siblings 225, male only 258 , female only 251, both male and female 273) (Kruskal-Wallis test, adjusted $p=0.0093$ ). We further observed that number of male siblings correlated with an increase in bacterial (none vs two or more, median richness 265 vs 330) (Wilcoxon test, adjusted $p=0.0004$ ) and fungal richness (none vs two or more, median richness 225 vs 267) (Wilcoxon test, adjusted $p=0.0047$ ). On the other hand, we did not observe any significant changes in bacterial (none vs two or more, median richness 265 vs 321) (Wilcoxon test, adjusted $p=0.1$ ) or fungal richness (none vs two or more, median richness 225 vs 257) (Wilcoxon test, adjusted $p=0.073$ ) in relation to increase in female siblings.

The bacterial microbial community (beta diversity) was significantly affected by the type of living environment, pets, the season of dust samples collection, and presence of siblings (PERMANOVA for weighted Unifrac, $p=0.001, R^{2}=0.008 ; p=0.005, R^{2}=0.007 ; p=$ $0.001, R^{2}=0.01$; and $p=0.026, R^{2}=0.003$, respectively). With the exception of pets and siblings, this was also the case for the fungal microbial community (PERM ANOVA for weighted Unifrac, $p=0.001, R^{2}=0.014$ and $p=0.001, R^{2}=0.105$, respectively) (Table 1$)$. We next investigated the interaction between all the significant factors and look for the marginal effects. We performed PERMANOVA for weighted Unifrac distance; environmental factors namely season had the largest interaction with bacterial and fungal bed dust microbiome composition $\left(p=0.001, R^{2}=0.021 ; p=0.001, R^{2}=0.084\right.$, respectively) (Table S15).

\section{Influence of pets on bed dust microbiome}

Various environmental factors influenced the bed dust microbiome composition (Table 1), and we performed in-depth evaluations of the effects of pets. Among the families, 87/577 (15.1\%) had cat only, 69/577 (11.9\%) had dogs only, and 32/577 (5.5\%) had both cat and dog. 


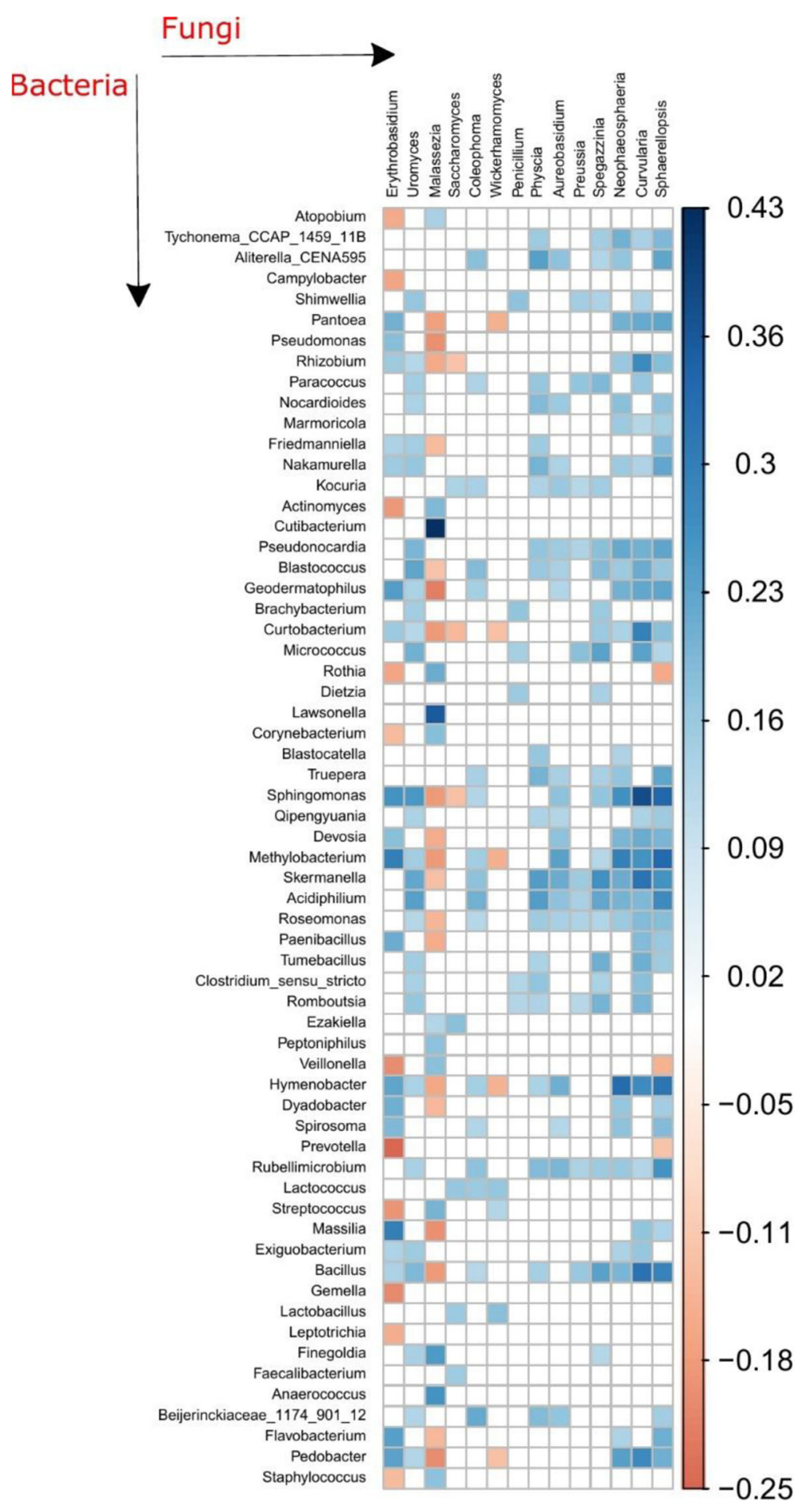

Fig. 2 Spearman correlation by genus abundance. Only significant values ( $p<0.05$ after FDR adjustment) are shown. Correlation inferred for the bed dust microbiome based on bacteria and fungi combined. Orange and blue represents significant negative correlations and positive correlations. Darker color represents stronger correlations

We observed that the bacterial alpha diversity were not significantly associated with the presence of either a cat or a dog only, but significantly higher in homes with both cat and dog (Kruskal-Wallis test, $p_{\text {observed }}=0.0039$, $\left.p_{\text {shannon }}=0.066, p_{\text {chao } 1}=0.0021\right)($ Fig. 3$)$, whereas fungal alpha diversity was not influenced by the pet ownerships (Kruskal-Wallis test, $p_{\text {observed }}=0.52, p_{\text {shannon }}=0.92$, $\left.p_{\text {chao1 }}=0.46\right)($ Fig. S9). 
Table 1 The effects of environmental factors on alpha and beta diversity on the bed dust microbiome

\begin{tabular}{|c|c|c|c|c|c|c|c|c|}
\hline Category & Variable & $\begin{array}{l}\text { Overall } \\
n(\%)\end{array}$ & $\begin{array}{l}\text { Bacterial } \\
\text { Alpha diversity } \\
\text { (median richness) }\end{array}$ & $\begin{array}{l}\text { Bacterial } \\
\text { Alpha } \\
\text { diversity } \\
\text { Adjusted } \\
p \text { value }\end{array}$ & $\begin{array}{l}\text { Bacterial } \\
\text { Beta } \\
\text { diversity } \\
R^{2} / p \\
\text { value }\end{array}$ & $\begin{array}{l}\text { Fungal } \\
\text { Alpha diversity } \\
\text { (median richness) }\end{array}$ & $\begin{array}{l}\text { Fungal } \\
\text { Alpha } \\
\text { diversity } \\
\text { Adjusted } \\
p \text { value }\end{array}$ & $\begin{array}{l}\text { Fungal } \\
\text { Beta } \\
\text { diversity } \\
R^{2} / p \\
\text { value }\end{array}$ \\
\hline & $n$ & 577 & & & & & & \\
\hline Sex & Male & $\begin{array}{l}301 \\
(52.2)\end{array}$ & & & & & & \\
\hline \multirow[t]{3}{*}{ Income level* } & Low & $52(9)$ & 308 & \multirow[t]{3}{*}{0.46} & \multirow{3}{*}{$\begin{array}{l}0.004 / \\
0.132\end{array}$} & 228 & \multirow[t]{3}{*}{0.51} & \multirow{3}{*}{$\begin{array}{l}0.003 / \\
0.417\end{array}$} \\
\hline & Medium & $\begin{array}{l}302 \\
(52.3)\end{array}$ & 285 & & & 246 & & \\
\hline & High & $\begin{array}{l}222 \\
(38.5)\end{array}$ & 274 & & & 246 & & \\
\hline \multirow[t]{2}{*}{ Type of home } & House $^{\uparrow}$ & $\begin{array}{l}316 \\
(54.8)\end{array}$ & 294 & 0.0089 & $\begin{array}{l}0.003 / \\
0.076\end{array}$ & 251 & 0.0016 & $\begin{array}{l}0.003 / \\
0.139\end{array}$ \\
\hline & Apartment & $\begin{array}{l}231 \\
(40)\end{array}$ & 269 & & & 230 & & \\
\hline \multirow[t]{2}{*}{$\begin{array}{l}\text { Type of living } \\
\text { environment }\end{array}$} & Rural $^{\uparrow}$ & $\begin{array}{l}251 \\
(43.5)\end{array}$ & 298 & 0.0004 & $\begin{array}{l}0.008 / \\
0.001\end{array}$ & 246 & 0.14 & $\begin{array}{l}0.014 / \\
0.001\end{array}$ \\
\hline & Urban & $\begin{array}{l}295 \\
(51.1)\end{array}$ & 266 & & & 242 & & \\
\hline \multirow[t]{3}{*}{ Pets } & Cat & $\begin{array}{l}87 \\
(15.1)\end{array}$ & 292 & 0.0039 & $\begin{array}{l}0.007 / \\
0.005\end{array}$ & 255 & 0.52 & $\begin{array}{l}0.004 / \\
0.468\end{array}$ \\
\hline & Dog & $\begin{array}{l}69 \\
(11.9)\end{array}$ & 294 & & & 252 & & \\
\hline & Both $^{\uparrow}$ & $\begin{array}{l}32 \\
(5.5)\end{array}$ & 346 & & & 247 & & \\
\hline \multirow[t]{4}{*}{$\begin{array}{l}\text { Season of dust } \\
\text { sample collection }\end{array}$} & $\begin{array}{l}\text { Winter (December, } \\
\text { January, February) }\end{array}$ & $\begin{array}{l}140 \\
(24.5)\end{array}$ & 272 & 0.97 & $\begin{array}{l}0.01 / \\
0.001\end{array}$ & 233 & $1.3 e-05$ & $\begin{array}{l}0.105 / \\
0.001\end{array}$ \\
\hline & $\begin{array}{l}\text { Spring }{ }^{\uparrow} \text { (March, April, } \\
\text { May) }\end{array}$ & $\begin{array}{l}115 \\
(20.1)\end{array}$ & 288 & & & 266 & & \\
\hline & $\begin{array}{l}\text { Summer (June, July, } \\
\text { August) }\end{array}$ & $\begin{array}{l}149 \\
(26)\end{array}$ & 283 & & & 262 & & \\
\hline & $\begin{array}{l}\text { Autumn (September, } \\
\text { October, November) }\end{array}$ & $\begin{array}{l}168 \\
(29.4)\end{array}$ & 277 & & & 229 & & \\
\hline Race & Caucasian & $\begin{array}{l}552 \\
(95.7)\end{array}$ & 281 & 0.12 & $\begin{array}{l}0.002 / \\
0.054\end{array}$ & 243 & 0.9 & $\begin{array}{l}0.001 / \\
0.442\end{array}$ \\
\hline \multirow[t]{2}{*}{ Siblings } & No & $\begin{array}{l}132 \\
(22.87)\end{array}$ & 265 & 0.03 & $\begin{array}{l}0.003 / \\
0.026\end{array}$ & 225 & 0.0023 & $\begin{array}{l}0.0023 / \\
0.329\end{array}$ \\
\hline & Yes $^{\uparrow}$ & $\begin{array}{l}329 \\
(57.02)\end{array}$ & 298 & & & 255 & & \\
\hline \multirow[t]{4}{*}{ Siblings } & No & $\begin{array}{l}132 \\
(22.87)\end{array}$ & 265 & 0.049 & $\begin{array}{l}0.009 / \\
0.003\end{array}$ & 225 & 0.0093 & $\begin{array}{l}0.011 / \\
0.053\end{array}$ \\
\hline & Male only & $\begin{array}{l}140 \\
(24.26)\end{array}$ & $311^{\uparrow}$ & & & $258^{\uparrow}$ & & \\
\hline & Female only & $\begin{array}{l}121 \\
(20.97)\end{array}$ & 284 & & & $251^{\uparrow}$ & & \\
\hline & Both male and female & $\begin{array}{l}68 \\
(11.78)\end{array}$ & 290 & & & $273^{\uparrow}$ & & \\
\hline \multirow[t]{3}{*}{$\begin{array}{l}\text { Number of male } \\
\text { siblings }\end{array}$} & None & $\begin{array}{l}132 \\
(22.87)\end{array}$ & 265 & 0.0015 & $\begin{array}{l}0.007 / \\
0.33\end{array}$ & 225 & 0.0062 & $\begin{array}{l}0.0003 / \\
0.99\end{array}$ \\
\hline & One & $\begin{array}{l}114 \\
(19.75)\end{array}$ & 308 & & & 255 & & \\
\hline & Two or more ${ }^{\uparrow}$ & $\begin{array}{l}26 \\
(4.5)\end{array}$ & 330 & & & 267 & & \\
\hline
\end{tabular}


Table 1 The effects of environmental factors on alpha and beta diversity on the bed dust microbiome (Continued)

\begin{tabular}{|c|c|c|c|c|c|c|c|c|}
\hline Category & Variable & $\begin{array}{l}\text { Overall } \\
n(\%)\end{array}$ & $\begin{array}{l}\text { Bacterial } \\
\text { Alpha diversity } \\
\text { (median richness) }\end{array}$ & $\begin{array}{l}\text { Bacterial } \\
\text { Alpha } \\
\text { diversity } \\
\text { Adjusted } \\
p \text { value }\end{array}$ & $\begin{array}{l}\text { Bacterial } \\
\text { Beta } \\
\text { diversity } \\
R^{2} / p \\
\text { value }\end{array}$ & $\begin{array}{l}\text { Fungal } \\
\text { Alpha diversity } \\
\text { (median richness) }\end{array}$ & $\begin{array}{l}\text { Fungal } \\
\text { Alpha } \\
\text { diversity } \\
\text { Adjusted } \\
p \text { value }\end{array}$ & $\begin{array}{l}\text { Fungal } \\
\text { Beta } \\
\text { diversity } \\
R^{2} / p \\
\text { value }\end{array}$ \\
\hline \multirow[t]{3}{*}{$\begin{array}{l}\text { Number of female } \\
\text { siblings }\end{array}$} & None & $\begin{array}{l}132 \\
(22.87)\end{array}$ & 265 & 0.29 & $\begin{array}{l}0.008 / \\
0.33\end{array}$ & 225 & 0.11 & $\begin{array}{l}0.003 / \\
0.95\end{array}$ \\
\hline & One & $\begin{array}{l}97 \\
(16.81)\end{array}$ & 274 & & & 248 & & \\
\hline & Two or more & $\begin{array}{l}24 \\
(4.16)\end{array}$ & 321 & & & 257 & & \\
\hline
\end{tabular}

${ }^{\wedge}$ Alpha diversity were calculated based on observed richness and significance were calculated using the Wilcoxon test (for two groups) and Kruskal-Wallis test (for three or more groups), FDR corrected

${ }^{*}$ Effects were quantified with $R^{2}$, and $p$ values, as determined by PERMANOVA on weighted UniFrac distances. Significant adjusted $p$ values $(p<0.05)$ are shown in bold

${ }^{\uparrow}$ The significant increase in alpha diversity of bacterial and/or fungal microbiome

*Income level is categorize into low $(<€ 50,000 /$ year), medium $(€ 50,000-€ 110,000 /$ year), and high (>€110,000/year)

We used the phylogeny-based weighted UniFrac method to assess the relatedness between samples from homes that had dogs and/or cats using principal coordinate analysis (PCoA). We found a small, but significant, effect on the bacterial community composition $\left(p_{\text {PERMANOVA }}=0.003, R^{2}=0.007\right)$, but no significant effect on the fungal community composition ( $p_{\text {PERMANOVA }}=$ $0.9, R^{2}=0.004$ ) (Fig. S10). Compared to homes without cats or dogs, we found that homes that had both cat and dog had over-representation of 19 taxa in infant beds, belonging to the phyla Firmicutes and Proteobacteria (Fig. 4, Table S7), and under-representation of 6 taxa, belonging to Cyanobacteria and Proteobacteria. Among these phyla, genera such as Gemella, Staphylococcus, and Sphingomonas were significantly over-represented ( $\log _{10}$ (LDA score) $>4, p<0.05$ ), and Enhydrobacter genera were significantly under-represented $\left(\log _{10}(\right.$ LDA score $\left.)>4, p<0.05\right)$.

In homes with either a cat or a dog, the bacterial microbiota appeared to be less influenced than homes with both (Fig. 3). Homes with a dog had overrepresentation of 21 taxa compared to homes that had no pets, belonging to the phyla Firmicutes, Fusobacteria, Proteobacteria, Cyanobacteria, and Actinobacteria, whereas homes with a cat had over-representation of 3 taxa, belonging to phylum Actinobacteria (Table S8). Genera belonging to Paeniclostridium, Atopobium, Tychonema, and Acinetobacter ( $\log _{10}$ (LDA score) > 3.5, $p<0.05)$ were significantly more abundant in the homes that have only dog, whereas Turicella $\left(\log _{10}\right.$ (LDA score) $>3.5, p<0.05)$ was significantly more abundant in the homes that have only cat (Table S9).

Furthermore, homes with both cat and dog had overrepresentation of 38 taxa, belonging to the phyla Ascomycota, Basidiomycota, Chytridiomycota, and Mortierellomycota. Genera belonging to Neophaeosphaeria, Mortierella, Preussia, Tylospora, Spizellomyces, Oleoguttula, and Monilochaetes $\left(\log _{10}\right.$ (LDA score) $>3.5, p<$ $0.05)$ were the significant ones that were over- represented in the homes that had both cat and dog (Table S10). Genera belonging to Setosphaeria, Peziza, Melanogaster, Lodderomyces, Preussia, Curvularia, and Dirkmeia $\left(\log _{10}\right.$ (LDA score) $\left.>3.5, p<0.05\right)$ (Table S11) were significantly more abundant in the homes that have only dog, whereas Oleoguttula, Curvularia, and Caloplaca $\left(\log _{10}(\right.$ LDA score $\left.)>3.5, p<0.05\right)$ were significantly more abundant in the homes that have an only cat (Table S12).

\section{Influence of living environment (rural or urban) on bed dust microbiome}

Bacterial richness and composition of the bed dust were highly influenced by the living environment (rural or urban) (Table 1). We further investigated and identified the taxa at genus level between rural and urban living environments. We found 353 genera in the bed dust from rural environment that were not present in the bed dust from urban environment (Table S13, Fig. S11a). In addition, we performed differentially abundant analysis using Wilcoxon tests to identify the taxa with significantly different abundance between the two groups (Fig. S11b). Paracoccus, Micrococcus, and Sphingomonas were the top three significantly more abundant taxa in the rural environment (adjusted $p$ value $<0.05$ ). Moreover, genera belonging to order Rickettsiales were significantly more abundant in the urban environment (adjusted $p$ value $<0.05$ ).

\section{Seasonal effect on other environmental factors}

To test for interactions between the season of sampling and the effect of environmental variables in the bed dust, we stratified the significant variables from Table 1 by the season of sampling. The effect of "type of living environment" and "type of home" on microbial diversity was consistent across seasons. However, the homes with both cat and dog only had a higher bacterial diversity in their bed dust when sampled in the fall and winter (Table S14). 

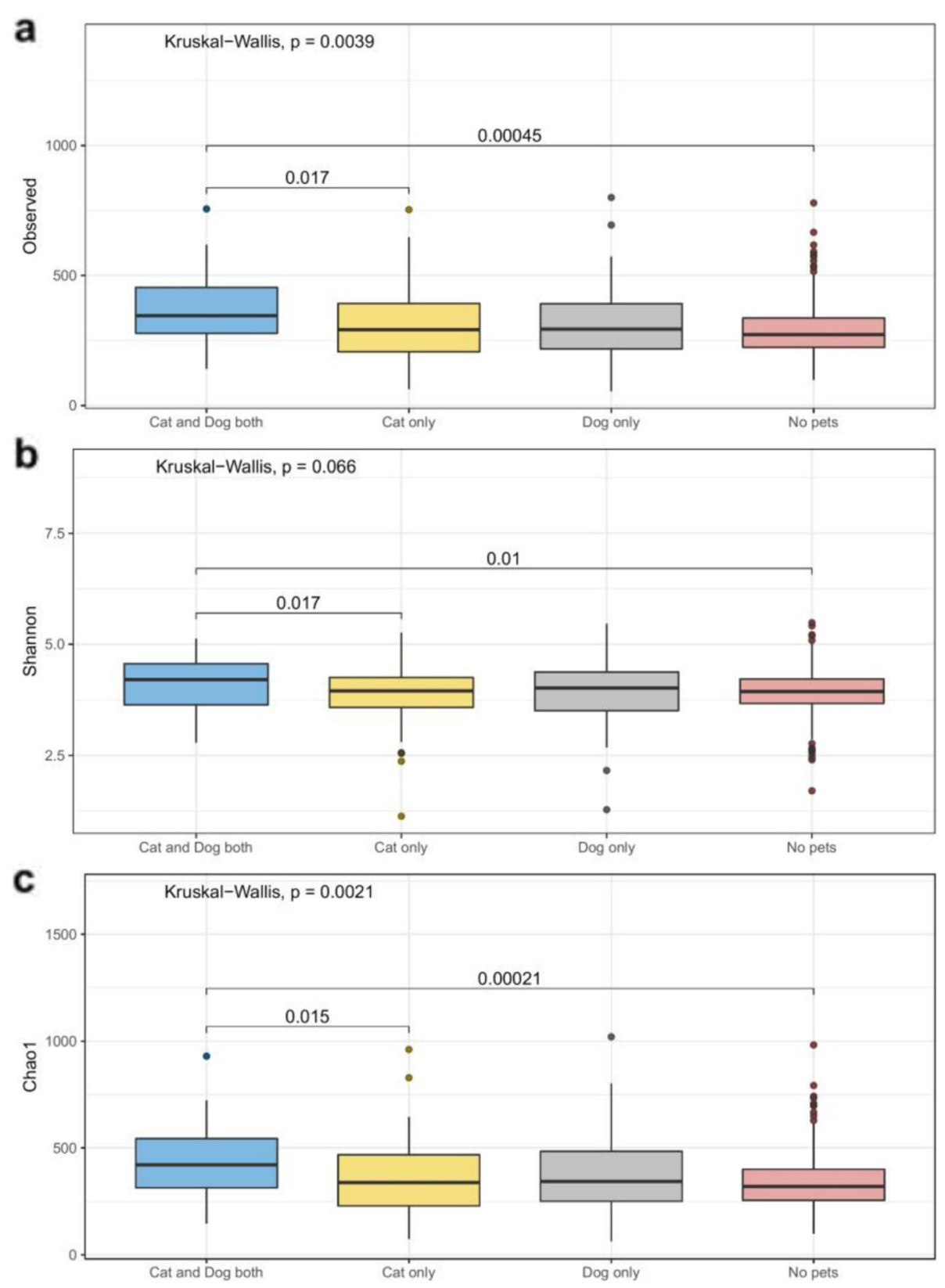

Fig. 3 Box plots of the three diversity metrics for bacteria [a observed, b Shannon diversity, and c Chao1 diversity] with homes categorized according to pet ownership. Alpha diversity was tested using the Kruskal-Wallis test, and Benjamini-Hochberg FDR method was used for $p$ value correction. After the global test was significant, a Wilcoxon test was performed to determine which group of the independent variable differs from each other group

\section{Correlations between the dust and airway microbiota}

Next, we evaluated whether associations existed between the two microbial compartments (beds dust when infants were 6 months old and airways at 3 months), possibly alluding to the importance of the dust microbiota on the infant airway composition. We observed significantly higher bacterial alpha diversity in bed dust compared to infant airways (Wilcoxon test, adjusted $p<1 \mathrm{e}$ -15) (Fig. 5a). Furthermore, bed dust and airway microbiota separated well by Bray-Curtis distance measures $\left(P_{\text {PERMANOVA }}<0.001\right)$ (Fig. $\left.5 \mathrm{~b}\right)$.

We applied several methods to identify relationships between bed dust and airway microbiota. Based on the Spearman correlations, we did not observe any significant correlations in alpha diversity $(p=0.9)$ (Fig. $5 \mathrm{~d}$ ). Furthermore, we tested for transfer between the dust and airway bacteria using presence-absence of shared genera and odds ratio analysis. Interestingly, we did not 


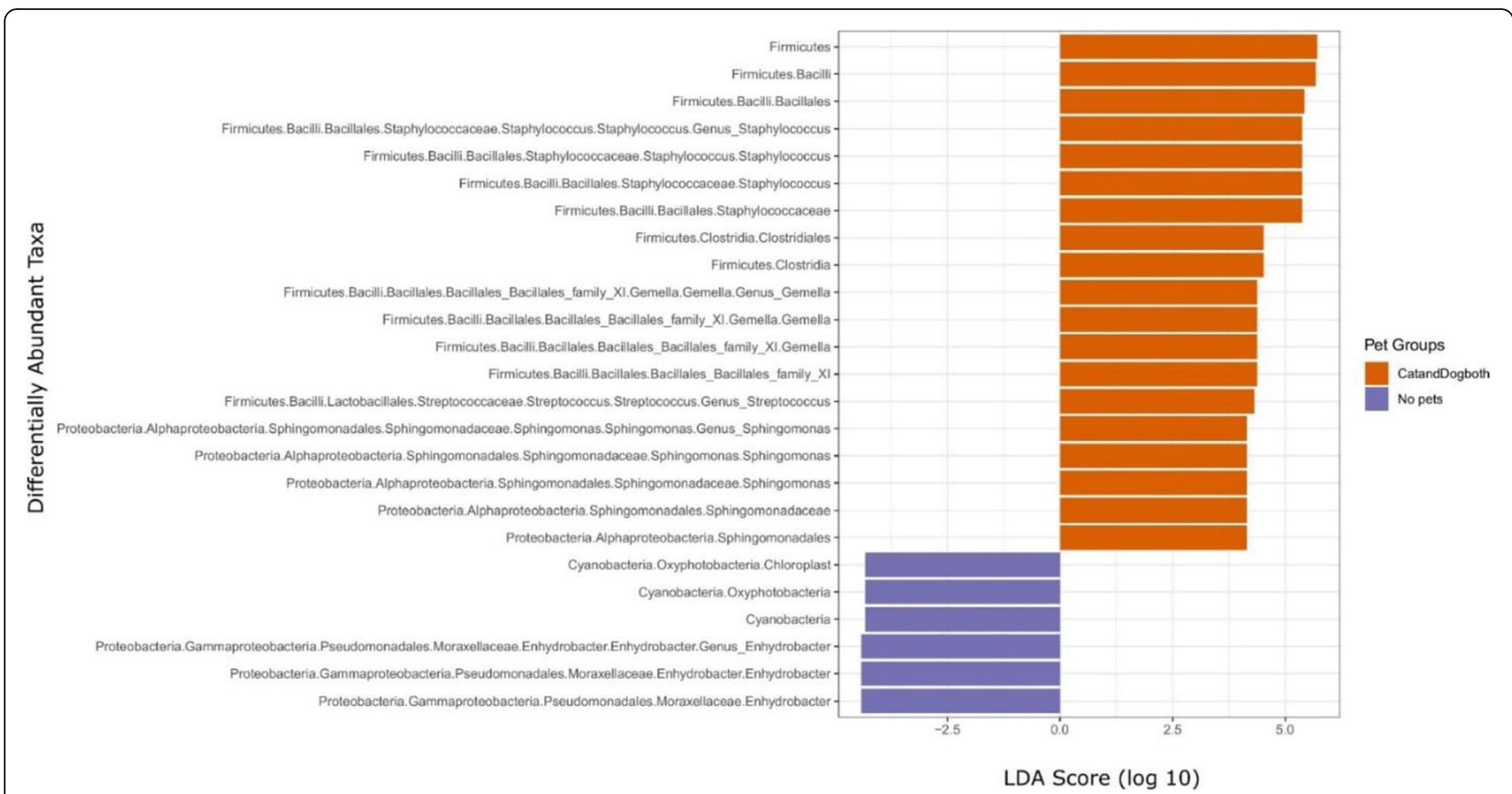

Fig. 4 Different abundances of bacterial communities between homes with both cat and dog and no pets. With LEfSe for data analysis and visualization, key ASVs were identified as differentiating between homes with both cat and dog and no pets. The threshold for the logarithmic LDA score was 4 and $p<0.05$ for the factorial Kruskal-Wallis test among classes

identify any significant sharing of genera using this method (Fig. S12). In addition, bed dust and airway samples from the same child were not more similar to each other than randomly paired dust and airway samples using Bray-Curtis distance (Wilcoxon test, adjusted $p=$ 0.3) (Fig. 5c).

When taking into account the relative abundance and looking for correlations, we found that the fungal community composition in bed dust did not show significant correlations with the airway bacterial community. However, we observed several bacterial genera in the bed dust that correlated significantly with bacterial abundances in the infant airways $(p<0.01)$ (Fig. 6). For example, Youngiibacter and Pseudolabrys in dust samples had many positive correlations with genera from the airway samples. Moreover, multiple genera in the bed dust samples such as Arachidicoccus, Pseudosphingobacterium, Calothrix, and Syntrophaceticus showed positive correlations with Luteibacter among airway samples.

\section{Discussion}

In this study, we determined that bacterial and fungal communities in bed dust are related to each other with positive correlations in alpha diversity and that they are both influenced by environmental factors. The presence of pets and type of living environment (rural or urban) are the dominant factors among those studied that most affect microbial communities.
We observed that the fungal microbiota composition of bed dust samples was dominated by fungi from the phyla Ascomycota and Basidiomycota (Fig. S4a). In accordance with previous work, Aureobasidium and Penicillium genera have commonly been identified in homes [27] at several sites such as floors [28] and kitchen sinks [29]. These shared features in community composition indicate that common taxa present elsewhere in homes are likely to be discovered in beds also.

Moreover, the bed dust samples were dominated by Gram-positive bacteria, including genera known to be associated with human sources such as Staphylococcus, Streptococcus, and Corynebacterium (Fig. S3d). These bacterial genera, which are commonly found on human skin [30], have been documented in other studies of the home microbiomes as well [31,32]. The human contribution to bacteria within the home is further confirmed in a study [5] showing the abundance patterns of bacterial taxa in samples from homes that closely resemble the microbial profiles of its human residents.

Environmental factors such as pets had a significant influence in shaping the bed dust microbiomes. Studies have shown that bacterial diversity increases significantly by the presence of a dog (but not by a cat) in a household $[4,14]$. We observed that bacterial diversity was increased significantly by the presence of both cat and dog in the home (Fig. 3) but not if either one was present alone. Many taxa associated with pet ownership have previously been associated with human health outcomes. 
a

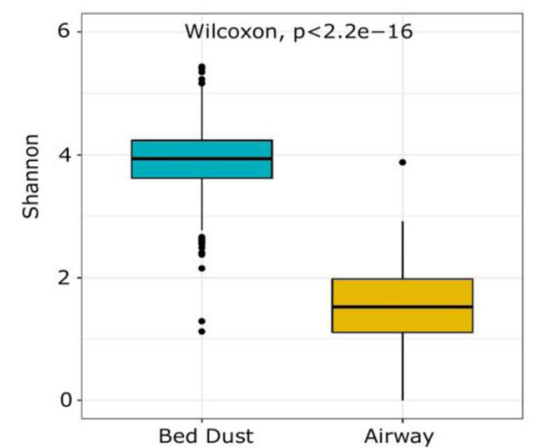

C

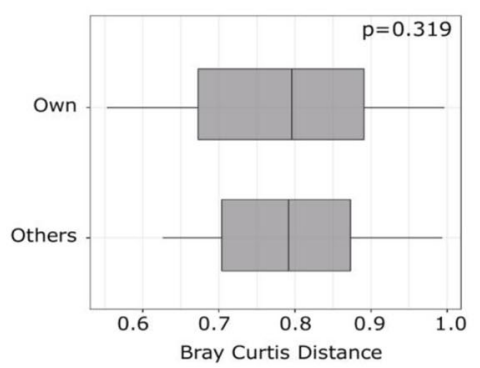

b

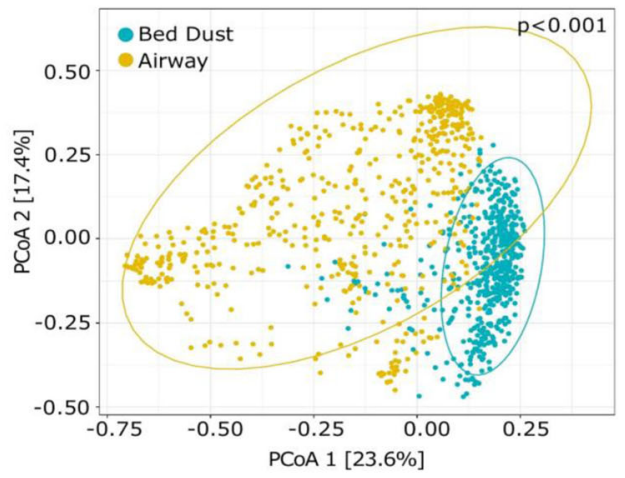

d

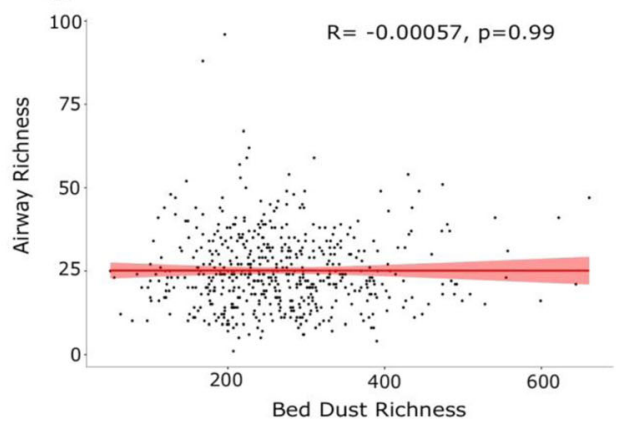

Fig. 5 Alpha and beta diversity comparison of airway and bed dust samples. a Box plot showing the Shannon diversity. Highly significant differences were observed in the diversity (Wilcoxon test, $p<2.2 \mathrm{e}-16$ ) between airway and bed dust samples. b Distances shown in the PCoA plot are based on Bray-Curtis diversity metrics. The bacterial microbiome of each sample is indicated with one dot. c Bray-Curtis distance between the dust-airway sample pairs for a specific child compared to the other random sample pair. "Own" represents the distance between specific children bed dust with their own airway samples. "Others" represents the distance between random pairs of children bed dust with random airway samples. $\mathbf{d}$ Associations between fungal and bacterial alpha diversity (observed richness) for a given sample. The shaded gray region represents $95 \%$ confidence intervals. Linear regression analysis: $p=0.99, R=-0.00057$ for observed richness

For example, Corynebacterium and Staphylococcus genera were associated with the homes that have both dog and cat. These genera are found mostly on skin and nose and may play an active role in host defense [33]. Acinetobacter was associated with homes that have only a dog. These genera, part of the human skin microbiota, may protect against allergic sensitization and inflammation [34].

Some studies have reported that the living environment (rural or urban) has little to no significant effect on bacterial or fungal diversity [35], whereas others have shown significant changes in the microbial diversity [36]. In our study, the effect of urbanization showed a significant effect on both bacterial and fungal diversity on the bed dust microbiome. Approximately $30 \%$ of bacterial genera present in the bed dust from rural areas were not found in bed dust samples collected from an urban living environment (Fig. S11). While a wide range of factors can influence the risk of developing asthma, rates of allergic asthma are higher for children living in more urbanized areas than in rural areas [37]. It has been hypothesized that these geographic differences in allergy rates can be attributed to people living in more urbanized areas being exposed to lower levels of microbial diversity [38], and our study supports the hypothesis.

Furthermore, we observed that having siblings in the household correlated with increased bacterial and fungal richness, similar to the data from Weikl et al. (2016) who found that households with more than three occupants had higher bacterial richness [39]. Earlier studies showed that fewer siblings in early life are associated with increased risks of developing asthma and other atopic diseases later in life [40]. Moreover, higher microbial diversity in the environment has been found to be inversely associated with asthma [25]. Together with our results, these suggest that siblings protect against asthma and atopic disease by increasing the bacterial and fungal richness, but further studies are needed to confirm this.

As no study we know of have investigated how the sex or siblings affect the bacterial or fungal richness, we stratified for the sex of siblings. Interestingly, we found that only male siblings significantly increased bacterial and fungal richness and correlated with the number of male siblings. In homes with only female siblings, fungal richness were significant increased, but we did not have 


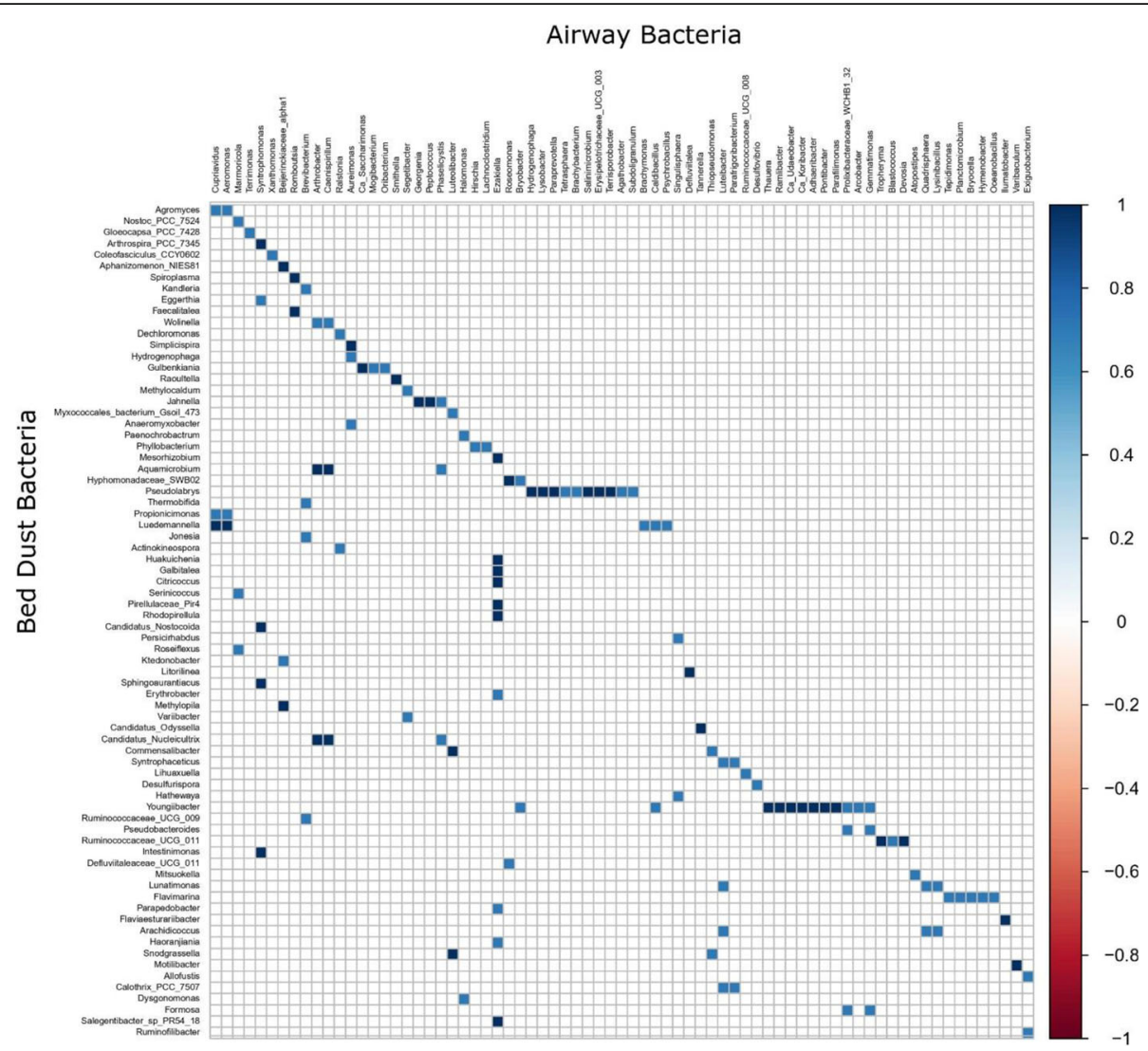

Fig. 6 Spearman correlation by genus abundance. Only significant values ( $p<0.05$ after FDR adjustment) are shown. Correlation inferred for bacterial bed dust microbiome with bacterial airway microbiome. Orange and blue colors represent significant negative correlations and positive correlations. Darker color represents stronger correlations

the statistical power to determine if the trend towards higher bacterial richness were significant. Additionally, we did not find any significant differences in the richness when comparing homes with either female or male siblings. While not directly comparable to our study population, it has been suggested that men shed more bacteria to their environment [7] and a study by Raju et al. found higher bacterial richness in saliva of boys compared to girls [41].

Interestingly, alpha diversity of the bacterial and fungal microbiome of the bed dust was significantly and positively correlated (Fig. 1c). To further understand the association between the bacterial and fungal microbiome in the bed dust samples, we observed numerous significant correlations at the genus level. In the fungal-fungal correlations, we observed mostly positive correlations with only Saccharomyces having negative correlations (to Spegazzinia, Curvularia, and Sphaerellopsis). Saccharomyces is a common genus in home dust and usually associated with humans [42]. For bacteria-bacteria correlations, the most abundant genera Staphylococcus and Streptococcus showed both positive and negative correlations with other genera. Staphylococcus and
Streptococcus are a typical part of the human microbiome and constantly interact with each other [30]. Moreover, we also observed an inter-domain correlation between bacteria and fungi and most of these correlations were positive, pointing at synergistic relationships or that they were transported to the bed dust together from the same source.

Not surprisingly, the bed dust bacterial microbiota was different from the airway bacterial microbiota. While both airway and bed dust samples harbored diverse microbial communities, the diversity of bacteria was higher in bed dust samples (Fig. 5a). The airway samples were dominated by genera from the families Streptococcaceae and Staphylococcaceae, as well as the genus Moraxella, which are mainly observed in the upper respiratory tracts of healthy children [43]. In our comparisons of bed dust and airway microbiota, based on OR, we did not observe any significant taxa that were shared between bed dust and infants' airway. However, based on the microbial relative abundance, we observed several positive correlations between airway bacterial and bed dust bacterial and fungal microbiomes. The biological significance of these positive correlations remains 
unknown, but as we found limited evidence of transfer, shared exposure reservoirs may be the cause. However, we cannot exclude the possibility that the difference in sampling time between the bed dust and airway samples might have caused this lack of evidence for transfer.

Our study has some limitations. We have used different DNA extraction kits for the airway and dust samples. Different types of extraction kits may have different biases in extraction efficiency, which in turn may affect the bacterial composition results. Moreover, we have used different sequencing primers for dust and airway microbiome $(\mathrm{V} 3-\mathrm{V} 4$ region for the bed dust samples and V4 region for the airway samples), and different PCR primers preferentially amplify different sets of taxa $[44,45]$. This may hamper the identification of transfer events on the ASV level. However, this should not affect the correlation analysis between the two compartments. Furthermore, we have collected the children's airway samples at 3 months of age whereas and the bed dust samples 3 months later. Collecting the samples at the same time point would have provided a stronger premise for association analyses, especially as seasonal differences in the microbiomes were found. However, we also observed that the sampling season did not seem to interact with the effect of other environmental variables, with the exception of the effect of pet ownership that was only found in the fall and winter. During fall and winter months, Danish people are likely to spend less time outdoors, but as pets need to visit there regularly during every season, they can act as vectors of bacteria from the outside. However, the stratification results in groups with quite low numbers, which can result in spurious findings, and should thus be interpreted with caution. Lastly, many of the fungal sequencing reads could not be assigned to specific taxa $(10.53 \%$ unclassified at the phylum level, $47.25 \%$ of reads being unclassified class level); this did limit our analysis and indicates that it might be relevant to revisit our analysis when better fungal reference databases are available.

\section{Conclusion}

In summary, our study finds evidence of interplay between bacterial and fungal diversity in the bed dust of young infants and that both bacterial and fungal composition are affected by environmental variables. We find limited evidence of transfer between the dust and developing airway microbiota. From early life, children are exposed to a multitude of environmental exposures, which may impact a healthy development perhaps through the microbiome of bed dust, which may act as the interface between environment and child.

\section{Methods}

\section{Study design and sample collection}

The study was embedded in the population-based COP$\mathrm{SAC}_{2010}$ prospective mother-child cohort of 736 women and their children followed from week 24 of pregnancy [26].

Beds dust was sampled by the parents when the infants were 6 months old. This was done using an external filter kit (DUSTREAM ${ }^{\circ}$ Collector, Indoor Biotechnologies, or Dust Collecting Device from ALK-Abello) attached to the family's vacuum cleaner with instructions to vacuum the sheets and pillow for $5 \mathrm{~min}$. Filters were then kept in the freezer for 3 days to kill dust mites and shipped to COPSAC where they were kept at $-20{ }^{\circ} \mathrm{C}$ until DNA extraction. The infant airway was sampled using hypopharyngeal aspirates obtained at 3 months of age, using a soft suction catheter passed through the nose and stored at $-80^{\circ} \mathrm{C}$ until DNA extraction [23].

\section{Covariates}

Information on educational level, household income, pet ownership, race, type of home, and home address was obtained during the scheduled visits to the research clinic. Living environment (rural/urban) was defined based on the land cover in a $3-\mathrm{km}$ radius based on children's birth address as previously described (Lehtimäki et. al., under review).

\section{DNA extraction and amplification}

Dust was released from the filter boxes, and $250 \mathrm{mg}$ was used for DNA extraction using the NucleoSpin ${ }^{\circ} 96$ Soil DNA Isolation Kit optimized for epMotion ${ }^{\circ}$ (MO-BIO Laboratories, Inc., Carlsberg, CA, USA) using the epMotion $^{\circ}$ robotic platform model (Eppendorf) under manufacturer's protocol. The bed dust samples were profiled with bacterial as well as fungal community using amplicon sequencing, using a two-step protocol. In the first step, we amplified the community specific rRNA target using general primers, and in the second step, we used primers with sequencing adaptors, barcodes, and the target sequence, so each sample could be uniquely identified post-sequencing. For fungi, we targeted the internal transcribed spacer, region 2 (ITS2), with the primers gITS7F (5'- GTGARTCATCGARTCTTTG-3') and ITS4ngs (5' - TTCCTSCGCTTATTGATATGC-3'). For bacteria, we targeted variable region $\mathrm{V} 3-\mathrm{V} 4$ of the $16 \mathrm{~S}$ rRNA gene, using forward primer 341f (5'- CCTA YGGGRBGCASCAG-3') and reverse primer 806r (5GGACTACHVGGGTWTCTAAT-3). Negative controls were included for the extraction and PCR amplification procedures. All final PCR products were purified using HighPrep ${ }^{\mathrm{TM}}$ PCR (MAGBIO, USA), based on paramagnetic beads technology. Then, it was normalized using SequalPrep ${ }^{\mathrm{TM}}$ Normalization plate kit (Invitrogen, USA). Further cleaning and concentration were done by using 
the DNA Clean \& Concentrator ${ }^{\mathrm{TM}}-5$ Kit (Zymo Research, Irvine, CA, USA). Concentrations were then determined using the Quant-iT ${ }^{\mathrm{m} x}$ High-Sensitivity DNA Assay Kit (Life Technologies).

The airway samples from the children at 3 months of age used in this study was a part of COPSAC $\mathrm{C}_{2010}$ cohort that was already published in Mortensen et al. [20] and Gupta et al. [43]. Genomic DNA was extracted for airway samples using the PowerMag ${ }^{\odot}$ Soil DNA Isolation Kit optimized for epMotion ${ }^{\circ}$ (MO-BIO Laboratories, Inc., Carlsberg, CA, USA) using the epMotion ${ }^{\circ}$ robotic platform model (Eppendorf) under manufacturer's protocol. The airway microbiota were profiled with the same method, but only for bacteria, targeting variable region V4 of the $16 \mathrm{~S}$ rRNA gene, using forward primer $515 \mathrm{f}$ ( $5^{\prime}$ - GTGCCA GCMGCCGCGGTAA-3') and 806r (5'-GGACTACHVG GGTWTCTAAT-3'). The rest of the steps were the same as mentioned above for dust samples.

\section{Sequencing}

Paired-end sequencing was performed on the Illumina MiSeq System (Illumina Inc., CA, USA), including 5\% PhiX as an internal control. All reagents used were from the MiSeq Reagent Kits v3 (Illumina Inc., CA, USA) for bed dust samples and MiSeq Reagent Kits v2 for airway samples. Automated cluster generation and paired-end sequencing with dual-index reads were performed with $2 \times 300$ bp for bed dust samples and $2 \times 250$ bp for airway samples. The sequencing output was generated as demultiplexed fastq-files for downstream analysis.

\section{Sequence analysis}

Primers were removed from the raw paired-end FASTQ files generated via MiSeq using "cutadapt" [46]. Further, reads were analyzed by QIIME2 [47] (qiime2-2018.11) pipeline through dada2 [58] to infer the ASVs present and their relative abundances across the samples. For bed dust samples, using read quality scores for the dataset, forward and reverse reads were truncated at $270 \mathrm{bp}$ and $220 \mathrm{bp}$, followed by trimming the $5^{\prime}$ end till $8 \mathrm{bp}$ for both forward and reverse reads, respectively; other quality parameters used dada2 default values for both $16 \mathrm{~S}$ rRNA gene and ITS sequencing. For airway samples, forward and reverse reads were truncated at $180 \mathrm{bp}$ and $160 \mathrm{bp}$; other parameters remain the same as mentioned above. For 16S rRNA gene sequencing, taxonomy was assigned using a pre-trained Naïve Bayes classifier (Silva database, release 132, 99\%ASV) [48], and for ITS sequencing, UNITE database (dynamic-2017-12-01) [49] were used.

\section{Quality control}

To ensure that our analyses were not confounded by spurious results, we first analyzed the alpha diversity of negative control samples (including PCR negative, extraction control) that produced sequencing reads and dust samples (Fig. S1). The DNA extraction and other negative controls had significantly lower observed richness than all dust samples (analysis of variance (ANOVA), $p<0.05$ ) for both fungal and bacterial data. Furthermore, profiles were significantly different for both bacterial and fungal microbiome by sample type (Fig. S2a, b). Sequencing contaminants (75 of 79,347 bacterial and 141 of 24,474 fungal ASVs) were identified based on the prevalence of ASVs in the negative control and removed using the decontam package (default parameters); this did not measurably affect the microbiota structure (Fig. S2c, d). We then removed the PCR and sequencing controls before downstream analysis. Moreover, samples that did not have a satisfactory sequencing of both 16S rRNA gene (minimum 3,000 reads per sample) and ITS (minimum 3,000 reads per sample) were removed. For airway samples, sequencing contaminants (14 of 3,692 bacterial ASVs) were identified based on the prevalence of ASVs in the negative control and removed using the decontam package (default parameters). The DNA extraction and other negative controls had significantly lower observed richness than all dust samples (analysis of variance (ANOVA), $p<0.05$ ) (Fig. S2e).

\section{Statistical analysis}

Data analysis was conducted in R (R Core Team, 2017). Initial preprocessing of the ASV table was conducted using the phyloseq package (v1.20.0) [50]. Further filtering was done by removing ASVs classified as archaea, chloroplast, or without phylum-level classification, from $16 \mathrm{~S}$ rRNA gene sequencing data as well as Rhizaria from ITS sequencing data. Sequencing contaminants were identified and removed using the decontam package [51]. To avoid the bias due to sampling depth, the ASVs table was multiple rarefied [43] to 6774 high-quality sequences per bed dust sample for 16S rRNA gene, 9,942 per bed dust sample for ITS, and 1,957 per sample for airway $16 \mathrm{~S}$ rRNA gene.

All downstream analyses were performed on this rarefied ASVs table unless mentioned. We used three alpha diversity indices, i.e., observed richness, Shannon diversity index, and Chao1 index. Furthermore, beta diversity was calculated using weighted and unweighted UniFrac metric and visualized by principal coordinates analysis (PCoA). Alpha and beta diversity was calculated using phyloseq v1.20.0 and visualized with ggplot2 v2.2.1 [52] in $\mathrm{R}$ v3.4.1. Comparison of community richness and diversity was assessed by the Kruskal-Wallis test between all the groups, and comparison between the two groups was done by Wilcoxon test with Benjamini-Hochberg FDR multiple test correction. Significance testing between the groups for beta diversity was assessed using 
permutational multivariate analysis of variance (PERM ANOVA) using the "vegan" package [53]. Marginal effect was calculated using the PERMANOVA analysis (for each significant environmental factor) using the following formula: adonis2(dist Type_of_enviornment + Pet + Type_of_home + Siblings + Season, by ="margin") for beta diversity.

\section{Microbial correlation and differentially abundant analysis} Considering the variable nature of $16 \mathrm{~S}$ compositional data, we estimated the core microbial group of ASVs within the samples with a presence in at least $30 \%$ of the study samples. The correlation analyses were performed at the genus level of the bed dust and airway samples. To better understand the dust community structure, characterize intra-community interactions, and identify potentially shared niches, the co-occurrence network analysis was performed and visualized by R. Spearman correlation analysis built into the function "rcorr" from the package "Hmisc" [54] was used to calculate the association at the genus level. $p$ values were adjusted for comparisons with the false discovery rate (FDR) algorithm after compositional transformation. The significance of the correlation adjusted $p$ value $<0.01$ was the threshold to define significant correlations. The correlation matrix of genera was visualized by the function "corrplot" in the package "corrplot" [55]. The linear regression analysis was visualized by the function "ggscatter" in the package "ggpubr" [56]. We analyzed the transfer of bacteria from bed dust to airway microbiome using Fisher's exact test by comparing the presence/absence of bacteria (at genus level) and calculated the odds ratio for transfer with a one-sided $p$ value. Only bacteria (at genus level) showing presence/absence in both the bed dust as well as the airway were included in the analysis. Inference for transfer of single bacteria (at genus level) was evaluated using Benjamini-Hochberg FDR correction. Furthermore, LEfSe [57] was used to identify the microbiological markers associated with a pet by linear discriminant analysis (LDA) effect size of cutoff 3.5. Other parameters were kept default. For rural and urban living environment, we have used the Wilcoxon tests.

\section{Supplementary information}

Supplementary information accompanies this paper at https://doi.org/10. 1186/s40168-020-00895-w.

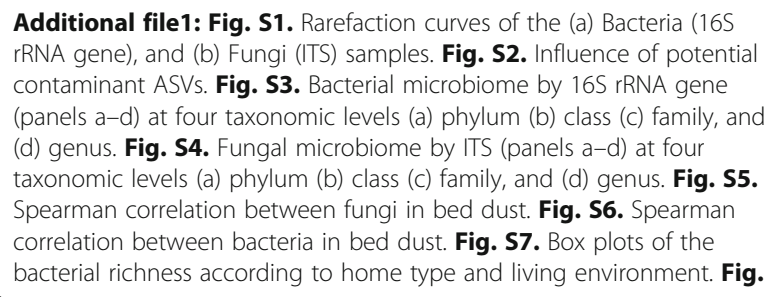

S8. Box plots of the fungal richness according to home type and living environment. Fig. S9. Box plots of fungal alpha-diversity according to pet ownership. Fig. S10. PCoA plot of (a) bacterial and (b) fungal community composition based on weighted Unifrac distance. Fig. S11. Differentially abundant analysis between rural and urban living environment. Fig. S12. The odds for transfer of taxa (at genus level) from dust to airway microbiota of children. Table S1. Characteristics of the study population. Table S2.Bacterial abundance in bed dust samples at phylum level. Table S3. Bacterial abundance in bed dust samples at genus level. Table S4. Fungal abundance in bed dust samples at phylum level. Table S5. Fungal abundance in bed dust samples at class level. Table S6. Fungal abundance in bed dust samples at genus level. Table S7. Differentially abundant bacterial taxa in bed dust samples for homes with dog and cat both. Table S8. Differentially abundant bacterial taxa in bed dust samples for homes with dog. Table S9. Differentially abundant bacterial taxa in bed dust samples for homes with cat. Table S10. Differentially abundant fungal taxa in bed dust samples for homes with dog and cat both. Table S11. Differentially abundant fungal taxa in bed dust samples for homes with dog. Table S12. Differentially abundant fungal taxa in bed dust samples for homes with cat. Table S13. Bacteria present in rural and urban environment at genus level. Table S14. The effects of season and environmental factors on bed dust alpha and beta-diversity. Table S15. The adjusted (marginal) effects of environmental factors on bed dust alpha and beta-diversity.

\section{Acknowledgements}

We express our deepest gratitude to the children and families of the COPSAC $_{2010}$ cohort study for all their support and commitment. We acknowledge and appreciate the unique efforts of the COPSAC research team.

\section{Authors' contributions}

S.G. is the main author of this paper. S.G. and M.S.M. performed the DNA extraction, construction of the ITS and 16S rRNA gene amplicon libraries, and sequencing. S.G. and X.L. performed the bioinformatics analysis. M.H. and J.L. helped in the dust sample processing. J.S. sampled the infants. S.G., M.H., J.L., M.S.M., M.A.R., U.T., and J.R. helped interpret the data. S.G. wrote the manuscript. This project was conceived and designed by S.J.S. and H.B. All authors have read, revised, and approved the manuscript.

\section{Funding}

This work was supported by the Strategiske Forskningsråd (Danish Council for Strategic Research) - 0603-00280B and Ministeriet Sundhed Forebyggelse (Ministry of Health) - 903516

\section{Availability of data and materials}

The dataset analyzed during the current study will be available, upon publication, in the Sequence Read Archive (SRA) repository under project id PRJNA605085 for bed dust samples (both bacterial and fungal raw sequencing reads). Airway samples were already published in our previous article and it is available in the Sequence Read Archive (SRA) repository, http://www.ncbi.nlm.nih.gov/bioproject/340273. All other data is available from the corresponding author.

Ethics approval and consent to participate

This study followed the principles of the Declaration of Helsinki, and was approved by the Ethics Committee for Copenhagen (The Danish National Committee on Health Research Ethics) (H-B-2008-093) and the Danish Data Protection Agency (2008-41-2599). Written informed consent was obtained from all participants.

Consent for publication

Written consent for publication has been obtained from the parents or legal guardians of all participants.

\section{Competing interests}

The authors declare no conflict of interest. 


\section{Author details}

${ }^{1}$ Section of Microbiology, Department of Biology, University of Copenhagen, Universitetsparken 15, bldg. 1, DK2100, Copenhagen, Denmark. ${ }^{2}$ Copenhagen Prospective Studies on Asthma in Childhood, Faculty of Health Sciences, Copenhagen University Hospital Gentofte, University of Copenhagen, Gentofte, Denmark. ${ }^{3}$ Host-Microbiota Interactions Laboratory, Wellcome Sanger Institute, Wellcome Genome Campus, Hinxton, UK. ${ }^{4}$ Section of Chemometrics and Analytical Technologies, Department of Food Science, University of Copenhagen, Rolighedsvej 30, 1958 Frederiksberg C, Copenhagen, Denmark.

Received: 6 July 2020 Accepted: 17 July 2020 Published online: 07 August 2020

\section{References}

1. Klepeis NE, Nelson WC, Ott WR, Robinson JP, Tsang AM, Switzer P, et al. The National Human Activity Pattern Survey (NHAPS): a resource for assessing exposure to environmental pollutants. J Expo Anal Environ Epidemiol. 2001; 11:231-52.

2. Barberán A, Dunn RR, Reich BJ, Pacifici K, Laber EB, Menninger HL, et al. The ecology of microscopic life in household dust. Proc Biol Sci. 2015;282.

3. Dannemiller KC, Gent JF, Leaderer BP, Peccia J. Influence of housing characteristics on bacterial and fungal communities in homes of asthmatic children. Indoor Air. 2016;26:179-92.

4. Kettleson EM, Adhikari A, Vesper S, Coombs K, Indugula R, Reponen T. Key determinants of the fungal and bacterial microbiomes in homes. Environ Res. 2015;138:130-5.

5. Lax S, Smith DP, Hampton-Marcell J, Owens SM, Handley KM, Scott NM, et al. Longitudinal analysis of microbial interaction between humans and the indoor environment. Science. 2014;345:1048-52.

6. Shelton BG, Kirkland KH, Flanders WD, Morris GK. Profiles of airborne fungi in buildings and outdoor environments in the United States. Appl Environ Microbiol. 2002;68:1743-53.

7. Hewitt KM, Gerba CP, Maxwell SL, Kelley ST. Office space bacterial abundance and diversity in three metropolitan areas. PLOS ONE. 2012;7: e37849.

8. Lax S, Sangwan N, Smith D, Larsen P, Handley KM, Richardson M, et al Bacterial colonization and succession in a newly opened hospital. Sci Transl Med. 2017;9.

9. Meadow JF, Altrichter AE, Kembel SW, Kline J, Mhuireach G, Moriyama M, et al. Indoor airborne bacterial communities are influenced by ventilation, occupancy, and outdoor air source. Indoor Air. 2014;24:41-8.

10. Nygaard $A B$, Charnock C. Longitudinal development of the dust microbiome in a newly opened Norwegian kindergarten. Microbiome. 2018; 6:159.

11. Adams RI, Bateman AC, Bik HM, Meadow JF. Microbiota of the indoor environment: a meta-analysis. Microbiome. 2015:3:49.

12. Loo EXL, Chew LJM, Zulkifli AB, Ta LDH, Kuo I-C, Goh A, et al. Comparison of microbiota and allergen profile in house dust from homes of allergic and non-allergic subjects- results from the GUSTO study. World Allergy Organ J. 2018;11:37.

13. Sitarik AR, Havstad S, Levin AM, Lynch SV, Fujimura KE, Ownby DR, et al. Dog introduction alters the home dust microbiota. Indoor Air. 2018;28:53947.

14. Lehtimäki J, Sinkko H, Hielm-Björkman A, Salmela E, Tiira K, Laatikainen T, et al. Skin microbiota and allergic symptoms associate with exposure to environmental microbes. Proc Natl Acad Sci U S A. 2018;115:4897-902.

15. Smith BP, Hazelton PC, Thompson KR, Trigg JL, Etherton HC, Blunden SL. A multispecies approach to co-sleeping: integrating human-animal cosleeping practices into our understanding of human sleep. Hum Nat. 2017; 28:255-73.

16. Pelucchi C, Galeone C, Bach J-F, La Vecchia C, Chatenoud L. Pet exposure and risk of atopic dermatitis at the pediatric age: a meta-analysis of birth cohort studies. J Allergy Clin Immunol. 2013;132:616-622.e7.

17. Lødrup Carlsen KC, Roll S, Carlsen K-H, Mowinckel P, Wijga AH, Brunekreef B, et al. Does pet ownership in infancy lead to asthma or allergy at school age? Pooled analysis of individual participant data from 11 European birth cohorts. PLoS ONE. 2012;7:e43214.

18. Peters RL, Allen KJ, Dharmage SC, Lodge CJ, Koplin JJ, Ponsonby A-L, et al. Differential factors associated with challenge-proven food allergy phenotypes in a population cohort of infants: a latent class analysis. Clin Exp Allergy. 2015;45:953-63.

19. Pyrhönen $K$, Näyhä $S$, Läärä E. Dog and cat exposure and respective pet allergy in early childhood. Pediatr Allergy Immunol. 2015;26:247-55.

20. Mortensen MS, Brejnrod AD, Roggenbuck M, Abu Al-Soud W, Balle C, Krogfelt KA, et al. The developing hypopharyngeal microbiota in early life. Microbiome. 2016;4:70.

21. Man WH, de Steenhuijsen Piters WAA, Bogaert D. The microbiota of the respiratory tract: gatekeeper to respiratory health. Nat Rev Microbiol. 2017; 15:259-70.

22. Thorsen J, Rasmussen MA, Waage J, Mortensen M, Brejnrod A, Bønnelykke K, et al. Infant airway microbiota and topical immune perturbations in the origins of childhood asthma. Nat Commun. 2019;10:5001.

23. Bisgaard H, Hermansen MN, Buchvald F, Loland L, Halkjaer LB, Bønnelykke K, et al. Childhood asthma after bacterial colonization of the airway in neonates. N Engl J Med. 2007;357:1487-95.

24. Teo SM, Mok D, Pham K, Kusel M, Serralha M, Troy N, et al. The infant nasopharyngeal microbiome impacts severity of lower respiratory infection and risk of asthma development. Cell Host Microbe. 2015;17:704-15.

25. Ege MJ, Mayer M, Normand A-C, Genuneit J, Cookson WOCM, Braun-

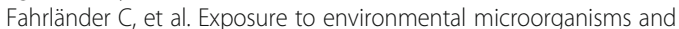
childhood asthma. N Engl J Med. 2011;364:701-9.

26. Bisgaard $\mathrm{H}$, Vissing NH, Carson CG, Bischoff AL, Følsgaard NV, Kreiner-Møller E, et al. Deep phenotyping of the unselected COPSAC2010 birth cohort study. Clin Exp Allergy. 2013;43:1384-94.

27. Coombs K, Taft D, Ward DV, Green BJ, Chew GL, Shamsaei B, et al. Variability of indoor fungal microbiome of green and non-green low-income homes in Cincinnati, Ohio. Sci Total Environ. 2018;610-611:212-8.

28. Hospodsky D, Qian J, Nazaroff WW, Yamamoto N, Bibby K, Rismani-Yazdi H, et al. Human occupancy as a source of indoor airborne bacteria. PLoS ONE. 2012; $7:$ :34867.

29. Flores GE, Bates ST, Caporaso JG, Lauber CL, Leff JW, Knight R, et al. Diversity, distribution and sources of bacteria in residential kitchens. Environ Microbiol. 2013;15:588-96.

30. Chen YE, Fischbach MA, Belkaid Y. Skin microbiota-host interactions. Nature. 2018:553:427-36.

31. Hanson B, Zhou Y, Bautista EJ, Urch B, Speck M, Silverman F, et al. Characterization of the bacterial and fungal microbiome in indoor dust and outdoor air samples: a pilot study. Environ Sci Process Impacts. 2016;18:71324.

32. Luongo JC, Barberán A, Hacker-Cary R, Morgan EE, Miller SL, Fierer N. Microbial analyses of airborne dust collected from dormitory rooms predict the sex of occupants. Indoor Air. 2017;27:338-44.

33. Cogen AL, Nizet $V$, Gallo RL. Skin microbiota: a source of disease or defence? Br J Dermatol. 2008;158:442-55.

34. Fyhrquist $N$, Ruokolainen $L$, Suomalainen A, Lehtimäki S, Veckman V, Vendelin J, et al. Acinetobacter species in the skin microbiota protect against allergic sensitization and inflammation. J Allergy Clin Immunol. 2014; 134:1301-1309.e11.

35. Barberán A, Ladau J, Leff JW, Pollard KS, Menninger HL, Dunn RR, et al. Continental-scale distributions of dust-associated bacteria and fungi. Proc Natl Acad Sci U S A. 2015;112:5756-61.

36. Parajuli A, Grönroos M, Siter N, Puhakka R, Vari HK, Roslund Ml, et al. Urbanization reduces transfer of diverse environmental microbiota indoors. Front Microbiol. 2018;9:84

37. Gern JE. The urban environment and childhood asthma study. J Allergy Clin Immunol. 2010;125:545-9.

38. Hanski I, von Hertzen L, Fyhrquist N, Koskinen K, Torppa K, Laatikainen T, et al. Environmental biodiversity, human microbiota, and allergy are interrelated. Proc Natl Acad Sci U S A. 2012;109:8334-9.

39. Weikl F, Tischer C, Probst AJ, Heinrich J, Markevych I, Jochner S, et al. Fungal and bacterial communities in indoor dust follow different environmental determinants. PLoS ONE. 2016;11:e0154131.

40. Ball TM, Castro-Rodriguez JA, Griffith KA, Holberg CJ, Martinez FD, Wright AL. Siblings, day-care attendance, and the risk of asthma and wheezing during childhood. N Engl J Med. 2000;343:538-43.

41. Raju SC, Lagström S, Ellonen P, de Vos WM, Eriksson JG, Weiderpass E, et al. Gender-specific associations between saliva microbiota and body size. Front Microbiol. 2019;10:767.

42. Viel A, Legras J-L, Nadai C, Carlot M, Lombardi A, Crespan M, et al. The geographic distribution of Saccharomyces cerevisiae isolates within three 
Italian neighboring winemaking regions reveals strong differences in yeast abundance, genetic diversity and industrial strain dissemination. Front Microbiol. 2017;8:1595.

43. Gupta S, Mortensen MS, Schjørring S, Trivedi U, Vestergaard G, Stokholm J, et al. Amplicon sequencing provides more accurate microbiome information in healthy children compared to culturing. Commun Biol. 2019; 2:291.

44. McLaren MR, Willis AD, Callahan BJ. Consistent and correctable bias in metagenomic sequencing experiments. Elife. 2019;8.

45. Sipos R, Székely AJ, Palatinszky M, Révész S, Márialigeti K, Nikolausz M. Effect of primer mismatch, annealing temperature and PCR cycle number on $16 \mathrm{~S}$ rRNA gene-targetting bacterial community analysis. FEMS Microbiol Ecol. 2007:60:341-50

46. Martin M. Cutadapt removes adapter sequences from high-throughput sequencing reads. EMBnet J. 2011:17:10

47. Bolyen E, Rideout JR, Dillon MR, Bokulich NA, Abnet CC, Al-Ghalith GA, et al. Reproducible, interactive, scalable and extensible microbiome data science using QIIME 2. Nat Biotechnol. 2019;37:852-7.

48. Quast C, Pruesse E, Yilmaz P, Gerken J, Schweer T, Yarza P, et al. The SILVA ribosomal RNA gene database project: improved data processing and webbased tools. Nucleic Acids Res. 2013;41:D590-6.

49. Köljalg U, Larsson K-H, Abarenkov K, Nilsson RH, Alexander IJ, Eberhardt U, et al. UNITE: a database providing web-based methods for the molecular identification of ectomycorrhizal fungi. New Phytol. 2005;166:1063-8.

50. McMurdie PJ, Holmes S. phyloseq: an R package for reproducible interactive analysis and graphics of microbiome census data. PLOS ONE. 2013;8:e61217.

51. Davis NM, Proctor DM, Holmes SP, Relman DA, Callahan BJ. Simple statistical identification and removal of contaminant sequences in marker-gene and metagenomics data. Microbiome. 2018;6:226.

52. Wickham H. ggplot2. New York: Springer New York; 2009.

53. Oksanen J, Blanchet FG. Package 'vegan'.

54. Harrell Jr FE, Harrell Jr MFE. Package 'Hmisc'. CRAN 2018 2019; 235-6.

55. Wei T, Simko V, Levy M, Xie Y, Jin Y, Zemla J. Package 'corrplot'. Statistician. 2017;56:316-24.

56. Kassambara A. ggpubr:"ggplot2" based publication ready plots. R package version 0.1. 6. 2017.

57. Segata N, lzard J, Waldron L, Gevers D, Miropolsky L, Garrett WS, et al. Metagenomic biomarker discovery and explanation. Genome Biol. 2011;12: R60.

58. Callahan BJ, McMurdie PJ, Rosen MJ, Han AW, Johnson AJA, Holmes SP. DADA2: High-resolution sample inference from Illumina amplicon data. Nature Methods 2016;13(7):581-3.

\section{Publisher's Note}

Springer Nature remains neutral with regard to jurisdictional claims in published maps and institutional affiliations.

Ready to submit your research? Choose BMC and benefit from:

- fast, convenient online submission

- thorough peer review by experienced researchers in your field

- rapid publication on acceptance

- support for research data, including large and complex data types

- gold Open Access which fosters wider collaboration and increased citations

- maximum visibility for your research: over $100 \mathrm{M}$ website views per year

At $\mathrm{BMC}$, research is always in progress.

Learn more biomedcentral.com/submissions 